\title{
Removal of Cationic Surfactants from Water by Adsorption on Attapulgite
}

\author{
Melina Kotti, Androniki Papafilippaki, Pinelopi Prassa, Afroditi Xirouhaki \\ Department of Environmental and Natural Resources Engineering, Technological Educational \\ Institute of Crete, Chania, Greece \\ Email: kotti@chania.teicrete.gr
}

How to cite this paper: Kotti, M., Papafilippaki, A., Prassa, P. and Xirouhaki, A. (2018) Removal of Cationic Surfactants from Water by Adsorption on Attapulgite. Computational Water, Energy, and Environmental Engineering, 7, 111-118. https://doi.org/10.4236/cweee.2018.73007

Received: January 10, 2018

Accepted: July 3, 2018

Published: July 6, 2018

Copyright $\odot 2018$ by authors and Scientific Research Publishing Inc. This work is licensed under the Creative Commons Attribution International License (CC BY 4.0).

http://creativecommons.org/licenses/by/4.0/

\begin{abstract}
The adsorption of the cationic surfactant, cetyltrimethylammonium chloride (CTMA) from aqueous solutions on attapulgite was studied. Attapulgite is a clay mineral that has many applications, especially in agriculture and industry. It has not been studied extensively compared with other clay minerals for its sorption properties in environmental applications. In the present work the adsorption capacity of CTMA on attapulgite was found that was high and was mostly due to ion exchange mechanism. Furthermore, the experimental data fitted well to the Langmuir isotherm.
\end{abstract}

\section{Keywords}

Adsorption, Attapulgite, Cationic Surfactants, Cetyltrimethylammonium Chloride

\section{Introduction}

Surfactants are synthetic products that are used extensively in different fields in daily life. They contain a polar (hydrophilic) group and an unpolar (hydrophobic) group. They are classified into four categories according to the charge of their hydrophobic group: anionic, cationic, non-ionic and amphoteric ones [1] [2]. The anionic surfactants are widely used as detergents and they have the greater consumption compared to the others. They tend to generate much higher foam levels than the other categories. The cationic surfactants are used for cleaning as disinfectants, for hair conditioners, for anti-rust additives for metals, for oil recovery from the oil reservoirs and for soil washing agents. The increasing use of surfactants has caused serious environmental problems such as eutrophication of lakes [3] [4]. This makes mandatory their removal from water. Adsorption has been recognized as an effective and promising technique and has been used 
in tertiary water and wastewater treatment. The pollutant that is adsorbed is called adsorbate (or sorbate) and the solid material is called adsorbent (or sorbent). The most common adsorbent material is the activated carbon, but it is high-cost and cannot be used at large scale. Other materials used for the same purpose are the clay minerals [5].

The cetyltrimethylammonium salt (CTMA) is a cationic surfactant that has been tested for its adsorption on clay minerals. The clay minerals are divided into swelling and non-swelling ones based on their structure and their interaction with water. It has been found [6] that the sorption on non-swelling minerals, such as kaolinite, was strongly affected by hydrophobic interactions, and is limited to the external surfaces, making the study more feasible.

When the cationic solutions come in constant with swelling minerals, such as montmorillonite, the surfactant molecules are adsorbed on mineral surfaces as well as interlayer spaces, making the study more complicated.

Attapulgite (palygorskite) is a clay mineral that belongs to the Fuller's earth group. It is a non-swelling mineral. It has different structure than the other clay minerals, as its 2:1 layers are distributed in chains and not in layers. It is considered to have a high surface area $\left(>150 \mathrm{~m}^{2} / \mathrm{g}\right)$ and a porous structure that is believed to contribute more to the sorptive capacity than its high surface area. Great attapulgite production is known to be that of USA and less of South Africa or other countries [7] [8].

Attapulgite is utilized in a variety of applications: industrial, agricultural and environmental. In industry, it is used as drilling fluid, as paper coating. In agriculture, it is used as soil amendment for improving the soil properties. For the environmental protection, attapulgite has been applied for the removal of heavy metals [9] [10] [11] and of organic compounds. Most studies referred to the removal of cationic dyes and humic acids from aqueous solutions [12] [13] [14] [15]. Besides, attapulgite has been applied for the partial desalination of sea water [16] and for the removal of dissolved organic carbon (DOC) from oily water [17]. It has not been tested for the removal of cationic surfactants from water.

In this work, we used CTMA chloride for sorbate and an attapulgite from Greece as sorbent in order to study the sorption properties of attapulgite and to remove the cationic surfactant from water. For the determination of CTMA concentration there are several methods, like anion chromatography and spectrophotometric methods. In the present work, we applied a spectrophotometric method that is rapid and simple.

\section{Materials and Methods}

\subsection{Materials}

The clay mineral attapulgite was purchased from GEOHELLAS company (Greece). The origin of the atttapulgite sample is from the region of Grevena (North Greece). It is a commercial product, specifically sold for agricultural use, and in the present study it was used without further pretreatment. The proper- 
ties of attapulgite are listed in Table 1 as specified by manufacturer's data sheet and by [18]. The cation exchange capacity (CEC) of this mineral is generally 200 - $300 \mathrm{meq} / \mathrm{kg}$ [8].

The surfactant cetyltrimethylammonium chloride (CTMA) was purchased from Aldrich and was of technical grade. The reagents sodium carbonate, sodium hydroxide, the dye bromophenol blue and the solvent

1,2-dichloromethane were obtained from Fluka and were of analytical grade.

\subsection{Batch CTMA Sorption}

For the CTMA kinetic study, two grams of attapulgite were added into $25 \mathrm{~mL}$ of CTMA solution with initial concentration of $10^{-3} \mathrm{M}$ in $50 \mathrm{~mL}$ centrifuge tubes. The mixtures were shaken at $150 \mathrm{rpm}$ for $1,2,4,6,24 \mathrm{~h}$. After, they were centrifuged at $4000 \mathrm{rpm}$ for $15 \mathrm{~min}$ and the supernatant was filtered through a 0.45 $\mu \mathrm{m}$ filter.

For the CTMA sorption study, 5, 10, 20, 50, $200 \mathrm{mg}$ of attapulgite were added into $25 \mathrm{~mL}$ of CTMA solution with concentration of $10^{-3} \mathrm{M}$ in $50 \mathrm{~mL}$ centrifuge tubes. The mixtures were shaken at $150 \mathrm{rpm}$ for $1 \mathrm{~h}$. After, they were centrifuged at $4000 \mathrm{rpm}$ for $15 \mathrm{~min}$ and the supernatant was filtered through a $0.45 \mu \mathrm{m}$ filter.

\subsection{Chemical Analysis}

CTMA has been determined by colorimetric methods [19] [20]. In this work it was determined by the colorimetric method described by [19]. An adequate volume of the aqueous solution was placed into a $25 \mathrm{~mL}$ volumetric flask. Then 5 $\mathrm{ml}$ of $10 \%$ carbonate solution, $1 \mathrm{~mL}$ of bromophenol blue (freshly prepared by dissolving $40 \mathrm{mg}$ of dye in $100 \mathrm{~mL}$ of $0.001 \mathrm{~N} \mathrm{NaOH}$ ) and $10 \mathrm{~mL}$ of 1,2-dichloroethane. The mixture was shaken for $5 \mathrm{~min}$ and after it was transferred in a separating funnel. After settling the organic phase was transferred to a stoppered centrifuge tube and centrifuged for $5 \mathrm{~min}$. The absorbance of the colored organic phase was measured at $600 \mathrm{~nm}$, with the solvent as blank.

The calibration was done by standard samples within the $0.02 \times 10^{-5}-1 \times 10^{-5}$ $M$ range.

\section{Results and Discussion}

\subsection{Determination of CTMA}

The absorbance (A) of standard solutions of CTMA was plotted versus their concentration, $\mathrm{C}(\mathrm{M})$ as is shown in Figure 1. In the same figure, the linear

Table 1. Properties of attapulgite from manufactuter's data sheet.

\begin{tabular}{cc}
\hline Properties & Value \\
\hline Density $\left(\mathrm{g} / \mathrm{cm}^{2}\right)$ & $0.45-0.60$ \\
Natural water content $(\%)$ & $100-220$ \\
Surface area $\left(\mathrm{m}^{2} / \mathrm{g}\right)$ & 220 \\
viscosity API & $27-45$ \\
\hline
\end{tabular}




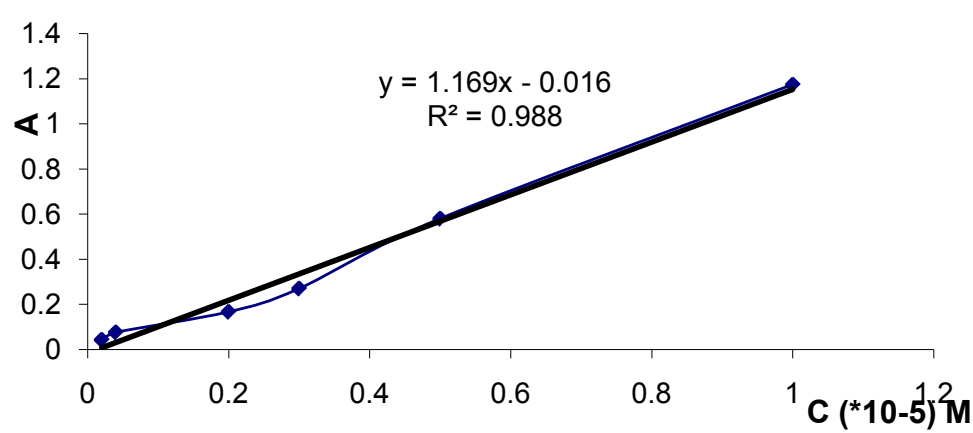

Figure 1. Calibration curve for CTMA plotting absorbance (A) vs. concentration $(\mathrm{C})$.

equation is presented that was used for the calculation of the unknown concentrations of CTMA and also the correlation coefficient, $\mathrm{R}^{2}$.

\subsection{Kinetic Results}

Figure 2 shows the results from the kinetic study. The concentration of CTMA in equilibrium, $\mathrm{Ce}(\mathrm{M})$ is plotted versus time (hours). It is clear from the figure that the equilibrium has been achieved in the first hour. The next batch experiments that have been described in the experimental part in order to calculate the isotherm were done in one hour.

\subsection{Sorption of CTMA}

The most common adsorption isotherms are the Langmuir and Freudlich ones. The Langmuir isotherm proposes that sorption occurs on homogenous active sites by monolayer sorption (surface with a finite number of identical sites) without interactions between sorbed molecules and has the following form:

$$
C_{s}=\frac{K_{L} \times S_{m} \times C_{e}}{1+K_{L} \times C_{e}}
$$

where $\mathrm{C}_{\mathrm{s}}$ is the amount of solute sorbed on solid at equilibrium (mol/g), $C_{e}$ is the solute concentration in liquid phase at equilibrium $(\mathrm{mol} / \mathrm{L}), S_{m}$ is the apparent sorption capacity or sorption maximum $(\mathrm{mol} / \mathrm{g})$ and $K_{L}$ is the Langmuir coefficient $(\mathrm{L} / \mathrm{mol})$ related to the adsorption energy.

Equation (1) can be rearranged to a linear form:

$$
\frac{C_{e}}{C_{s}}=\frac{1}{K_{L} \times S_{m}}+\left(\frac{1}{S_{m}}\right) \times C_{e}
$$

So that $K_{L}$ and $S_{m}$ can be determined by the linear equation.

Freudlich equation proposes that sorption occurs on heterogenous active sites and/or there are interactions between sorbed molecules leading to multilayer sorption. This isotherm is used widely, especially at low to medium concentration range and has the following form:

$$
C_{s}=K_{F} \times C_{e}^{n}
$$




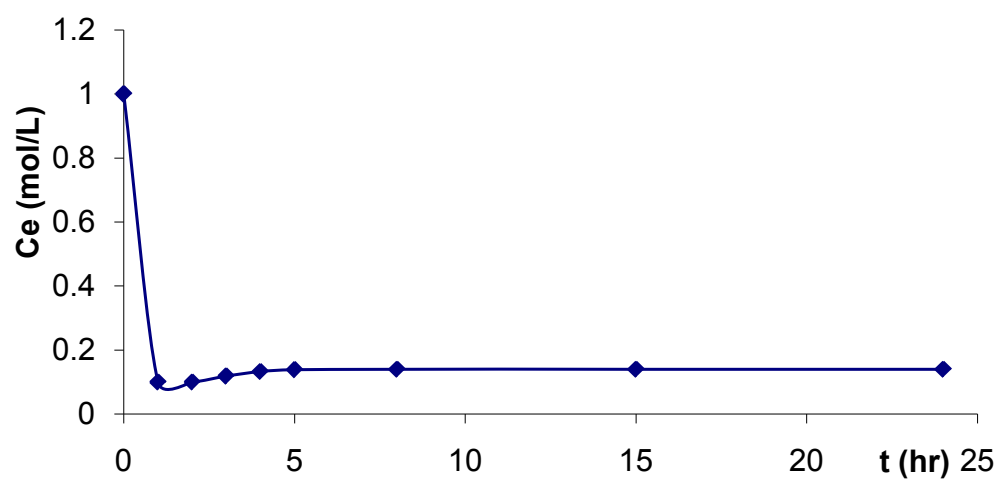

Figure 2. Plot of equilibrium concentration $C_{e}(M)$ vs. time (hours).

where $C_{s}$ is the amount of solute sorbed on solid at equilibrium (mol/g), $C_{e}$ is the solute concentration in liquid phase at equilibrium $(\mathrm{mg} / \mathrm{L}), K_{F}$ is the Freudlich coefficient $(\mathrm{L} / \mathrm{mol})$ indicating of the sorption capacity and $\mathrm{n}$ is a coefficient indicating of the sorption intensity.

Equation (3) can be rearranged to a linear form:

$$
\log C_{s}=n \times \log C_{e}+\log K_{F}
$$

The results from the isotherms are shown in Figure 3 and Figure 4. Comparing the two plots it is obvious because of the higher correlation coefficient that the adsorption equilibrium data fit much better to the Langmuir model. The sorption capacity $\left(S_{m}\right)$, as calculated from the slope of Equation (2), is 240 $\mathrm{mmol} / \mathrm{kg}$, a similar value with the CEC of this material $(264 \mathrm{meq} / \mathrm{kg})$, as was calculated by [8].

Generally, the mechanisms for the physical adsorption are: Van der Waals forces, hydrophobicity, hydrogen bonds, polarity and steric interaction, dipole dipole interaction, $\pi-\pi$ interaction. The mechanisms for the adsorption of cationic surfactants on different clay and zeolite minerals include: ion exchange and hydrophobic interactions.

There are many studies in literature about the adsorption of cetyltrimethylammonium bromide, but not of the chloride salt, on clay and zeolite minerals.

From the clay minerals, montmorillonite is reported mostly to have the greatest sorption capacity. The mechanisms for the adsorption of CTMA on montmorillonite were found to be both ion exchange and interactions such as induced and $\pi-\pi[21]$.

Kaolinite is another clay mineral that has also been studied. Harendra and Vipulanandan [22] have studied the adsorption of cetyltrimethylammonium bromide on kaolinite and blasted sand and found that kaolinite had the higher sorption capacity of the two. Kaolinite had a CEC of $15-20 \mathrm{meq} / \mathrm{kg}$ and a sorption capacity of $10 \mathrm{mmol} / \mathrm{kg}$.

$\mathrm{Li}$ and Gallus [23] also have studied the adsorption of cetyltrimethylammonium bromide on well clystallized kaolinite and on poorly clystallized kaolinite and found that the hydrophobic interaction was mostly responsible for the 


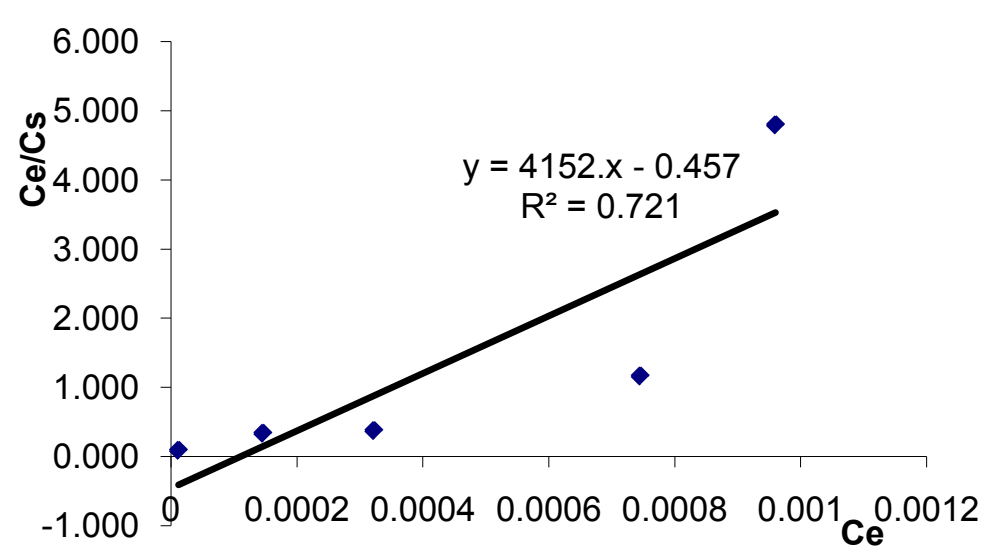

Figure 3. Plot of the Langmuir sorption isotherm of CTMA on attapulgite.

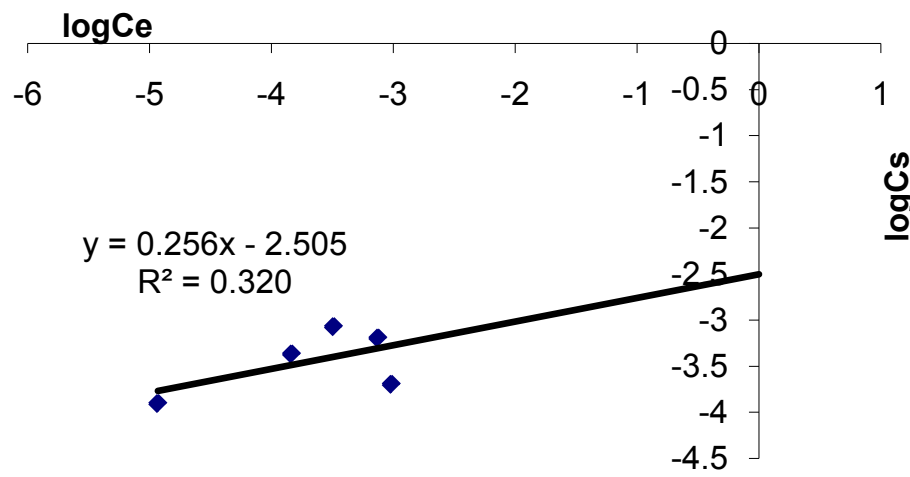

Figure 4. Plot of the Freudlich sorption isotherm of CTMA on attapulgite.

adsorption compared to cation exchange. Kaolinite there had a CEC of 30 - 37 $\mathrm{meq} / \mathrm{kg}$ and an almost twice sorption capacity of $58 \mathrm{mmol} / \mathrm{kg}$.

From the zeolite minerals, clinoptilolite is one of the most common and abundant ones.

Li [24] has studied the adsorption of cetyltrimethylammonium bromide on clinoptilolite and found a sorption capacity of $200 \mathrm{mmol} / \mathrm{kg}$, a value that is smaller than the sorption capacity found in the present work. The clinoptilolite had a CEC of $90-110 \mathrm{mmol} / \mathrm{kg}$.

Another research that used clinoptilolite as sorbent, with a very high CEC value of $1360 \mathrm{meq} / \mathrm{kg}$ and cetyltrimethylammonium bromide as sorbate [25], found a sorption capacity of 284 and the adsorption mechanism that was mostly the ion exchange.

Attapulgite has been found [16] that its sorption capacity for removing Ca, $\mathrm{Mg}, \mathrm{K}$ and $\mathrm{Na}$ from sea water is due to its ion exchange properties. The equilibrium data fitted best with the Langmuir isotherm. It showed a sorption capacity of $248 \mathrm{mmol} / \mathrm{kg}$ of $\mathrm{Na}$, slightly higher than the other ions. This result is similar with the result of the present study for CTMA.

Attapulgite has been investigated for the removal of heavy metals and for the removal of cationic dyes [12] [13] [14] [15]. The majority of these papers found 
that equilibrium data fitted best to the Langmuir isotherm.

\section{Conclusions}

From the results of this paper it is concluded that attapulgite is a very effective adsorbent material for the removal of the cationic compound cetyltrimethylammonium chloride from water. The sorption takes place mostly due to cation exchange and less to other interactions. The sorption capacity was found to be approximately the same with the CEC of the material. The experimental data fitted well with the Langmuir isotherm.

\section{References}

[1] Broze, G. (ed.) (1999) Handbook of Detergents, Part A: Properties. Marcel Dekker Inc., New York. https://doi.org/10.1201/b10985

[2] NIIR Project Consultancy Services (2013) The Complete Technology Book on Detergents. 2nd Edition, NIIR Board of Consultants Engineers, NIIR Project Consultancy Services, India.

[3] Lee, G.F. and Jones, R.A. (1986) Detergent Phosphate Bans and Eutrophication. Environ. SCI Technologies, 20, 330-331.

[4] Scott, M.J. and Jones, M.N. (2000) The Biodegradation of Surfactants in the Environment. Biochimica et Biophysica Acta (BBA)_Biomembranes, 1508, 235-251. https://doi.org/10.1016/S0304-4157(00)00013-7

[5] Cserhati, T., Forgacs, E. and Oros, G. (2002) Biological Activity and Environmental Impact of Anionic Surfactants. Environment International, 28, 337-348. https://doi.org/10.1016/S0160-4120(02)00032-6

[6] Xu, S. and Boyd, S.A. (1995) Cationic Surfactant Adsorption by Swelling and Nonswelling Layer Silicates. Langmuir, 11, 2508-2514. https://doi.org/10.1021/la00007a033

[7] Galan, E. (1996) Properties and Applications of Palygorskite-Sepiolite Clays. Clay Minerals, 31, 443-453. https://doi.org/10.1180/claymin.1996.031.4.01

[8] Chemeda, Y.C., Christidis, G.A., Tauhid Khan, N.M., Koutsopoulou, E., Hatzistamou, V. and Kelessidis, V.C. (2014) Rheological Properties of Palygorskite-Bentonite and Sepiolite-Bentonitemixed Clay Suspensions, Applied Clay Science, 90, 165-174. https://doi.org/10.1016/j.clay.2013.12.013

[9] Awadh, S.M. and Towfik, S.M. (2013) Sorption Mechanism and Capacity Evaluation of Palygorkite from Iraq to Remove $\mathrm{Pb}$ from Aqueous Solution. Journal of Geology and Geophysics, 2, 126-129.

[10] El-Mofty, S.E. and El-Shall, H. (2008) Adsorption Mechanism of Toxic Metal Ions by Clay (Attapulgite). Twelfth International Water Technology Conference, IWTC12, Alexandria, 27-30 March 2008, 403-413.

[11] Melnyk, L., Bessarab, O., Matko, S. and Malyovanyy, M. (2015) Adsorption of Heavy Metals Ions from Liquid Media by Palygorskite. Chemistry \& Chemical Technology, 9, 467-470. https://doi.org/10.23939/chcht09.04.467

[12] Wang, J., Han, X., Ma, H., Ji, Y. and Bi, L. (2011) Adsorptive Removal of Humic Acid from Aqueous Solution on Polyaniline/Attapulgite Composite. Chemical Engineering Journal, 173, 171-177. https://doi.org/10.1016/j.cej.2011.07.065

[13] Al-Futaisi, A., Jamrah, R. and Al-Hanai, R. (2007) Aspects of Cationic Dye Molecule Adsorption to Palygorskite. Desalination, 214, 327-342. 
https://doi.org/10.1016/j.desal.2006.10.024

[14] Chang, P.-H., Li, Z., Yu, T.-L., Munkhbayer, S., Kuo, T.-H., Hung, Y.-C. and Jean, J.-S. (2009) Sorptive Removal of Tetracycline from Water by Palygorskite. Journal of Hazardous Materials, 165, 148-155. https://doi.org/10.1016/j.jhazmat.2008.09.113

[15] Wang, M., Liao, L., Zhang, X. and Li, Z. (2012) Adsorption of Low Concentration Humic Acid from Water by Palygorskite. Applied Clay Science, 67, 164-168. https://doi.org/10.1016/j.clay.2011.09.012

[16] Nel, M., Waanders, F.B. and Fosso-Kankeu, E. (2014) Adsorption Potential of Bentonite and Attapulgite Clays Applied for the Desalination of Sea Water. Conference on Green Technology, Renewable Energy \& Environmental Engineering, Cape Town, 27-28 November 2014, 171-175.

[17] Haddabi, M.A., Vuthaluru, H., Znad, H. and Ahned, M. (2015) Attapulgite as Potential Adsorbent for Dissolved Organic Carbon from Oily Water. Wiley-VCH Verlag GmbH \& Co. KGaA, Weinheim. https://doi.org/10.1002/clen.201500073

[18] Kastritis, I.D., Kacandes, G.H. and Mposkos, E. (2003) The Palygorskite and Mg-Fe-Smectite Clay Deposits of the Ventzia Basin, Western Macedonia, Greece. Mineral Exploration and Sustainable Development, MillPress, Rotterdam.

[19] Van Stevenick, J. and Maas, M.M. (1965) A Colorimetric Method for Microquantities of Quaternary Ammonium Detergents. Recueil, 84, 1166-1168. https://doi.org/10.1002/recl.19650840908

[20] Few, A.V. and Ottewill, R.H. (1956) A Spectrophotometric Method for the Determination of Cationic Detergents. Journal of Colloid Science, 11, 34-38. https://doi.org/10.1016/0095-8522(56)90016-2

[21] Navratilova, Z., Wojtowicz, P., Vacculikova, L. and Sugarkova, V. (2007) Sorption of Alkkylammonium Cations on Montmorillonite. Acta Geodynamica et Geomaterialia, 4, 59-65.

[22] Harendra, S. and Vipulanandan, C. (2013) Sorption and Transport Studies of Cetyl Trimethylammonium Bromide (CTAB) and Triton X-100 in Clayey Soil. Journal of Environmental Sciences, 25, 576-584. https://doi.org/10.1016/S1001-0742(12)60070-9

[23] Li, Z. and Gallus, L. (2005) Surface Configuration of Sorbed Hexadecyltrimethylammonium on Kaolinite as Indicated by Surfarcant and Counterion Sorption, Cation Desorption and FTIR. Colloids and Surfaces A: Physicochemical and Engineering Aspects, 264, 61-67. https://doi.org/10.1016/j.colsurfa.2005.05.016

[24] Li, Z. (2007) Removal of Cationic Surfactants from Water Using Clinoptilolite Zeolite, from Zeolites to Porous MOF Materials. 40 th Anniversary of International Zeolite Conference, Beijing, 12-17th August 2007, 2098-2103.

[25] Haruyunyan, L.R. and Pirumyan, G.P. (2015) Purification of Waters from Anionic and Cationic Surfactants by Natural Zeolites. Chemistry and Biology, 1, 21-28. 